\title{
A Review of Paul Douglas Grant and Misha Boris Anissimov's Lilas: An Illustrated History of the Golden Ages of Cebuano Cinema
}

Benedict Salazar Olgado

\begin{abstract}
This archaeology, the archaeology of writings, of readings, of the palimpsest of past and future histories of Cebuano cinemas, is where we may begin to construct a more viable and less fanciful (and hopefully less mournful) narrative about Cebuano cinema and its afterlives. (Grant \& Anissimov, 2016, p. 21)
\end{abstract}

Knowing next to nothing about Cebuano Cinema, reading Lilas is akin to being in a beautiful poignant wake of someone I wish I had met. Presenting a volley of voices that attempts to make sense of the traces of a cinema that once was, Paul Douglas Grant and Misha Boris Anissimov wield theories, narratives, ephemera, oral histories, and a multitude of other para-cinematic materials with a commemorative and rallying air. But ultimately, everything punctuates an underlying nostalgia that reminds that one is mourning.

Grant's introduction is an excellent review and a critical homage to past literatures that should all be juxtaposed with Lilas. His theoretical explorations on the notions of cinema, history, and historiography vis-à-vis nationalism, regionalism, and imperialism could be read as masturbatory within what looks like a coffee table book. But through the skillful contextualization illustrated in his narrativization and exploration of the El Hijo Desediente claims, Grant is able to articulate both the underlying problems of writing about Cebuano cinema and the framework he uses in 
his study. He continues to do this in Part 1, which ends with an intriguing premise on "Third Cinema" and the "assemblage" of Cebuano cinema, hinting at reconceptualization or even possible counterhistorical narratives-a premise I wish the book dedicated a whole chapter on.

Lilas is both bold in its undertaking and apologetic of its limitations. Creating temporal demarcations between the 1950s and the 70s, Grant and Anissimov explore each period in dedicated parts. While both talk about the same cinematic tradition, there is a stark difference in their scope and focus. Grant attempts a narrativized filmography of its so-called Golden Age, covering production, distribution, and reception histories. In contrast, Anissimov presents fascinating profiles of key figures, including Gloria Sevilla and Justo C. Justo, amidst the looming sociopolitical backdrop of the Marcos regime and Tagalog Cinema.

Taken together, both parts present a wide range of historical inquiries that touch on institutional developments, auteurs and stars, policies and regulations, filmmaking, and audience studies. From the rise and fall of various production companies like Azucena Pictures to Chandra Romero's trophy incident at the 1st Visayan Film Festival, Lilas endeavors to present and at times interrogate such accounts. Tempered dramatics of the events unfold side-by-side critical analysis. For instance, the section on Cebu City Mayor Eulogio E. Borres's relations with his local cinema is a fascinating read on policy, exhibition, and reception that touches on economics and sociocultural histories. Such generative mechanisms are at play in Grant and Anissimov's narratives.

This broadness in approach is both the strength and weakness of Lilas. It is a rich text to break down as it attempts to be many things at once. It provides a coherent big picture, but it also leads one to yearn for more depth, complexity, and nuance. The section on Magnolia Films, for example, is filled with rapid accounts that leave one hanging as its contexts and implications are not fully explored. Such an open historization may then be frustrating for some and enthralling for others. Either way, it builds a longing to know more.

Making use mainly of newspapers and magazines, Grant and Anissimov move the focus away from film texts as they piece together a film culture beyond the screen. It is a framework that is also dictated by the lamentable reality that no known extant Cebuano film print has survived. Grant touches on this archival crisis briefly in the beginning of Part 1, where he discusses how the crisis shapes and limits his historical narration of the Golden Age. For a reader who has not seen any of the films he mentions, I noted the nostalgia that resonated throughout the book. This melancholy reaches its climax in Part 3, aptly entitled "Relics," where a translation of the serialization 
of The Batul of Mactan (1974) and a reprint of the comic serialization of Ang Medalyon nga Bulawan (1974) have been included. These works provide a glimpse into what Cebuano films used to be and serve as a painful reminder of their archival fragility.

That said, Grant and Anissimov skillfully make do and expand the limited cinematic traces they have to weave a riveting story. They present and critically question with equal weight scholastic claims, popular narratives, industry publicities, news reports, personal reminiscences, and government statements. They acknowledge that such materials all deserve space and analysis as part of a broader textual field of film history.

Where Lilas ends up unsuccessful though is the presentation of primary materials as "visual pleasure" as claimed in the book's preface and as was expected, given the coffee-table-book-like quality of the publication. While the images may easily draw in people who have recollections of these cinematic ephemera, the layout does not aptly serve the text and images and creates a disjoint between the two. There are some highlights like Figures 1.76 and 1.77, which serve as witty and poignant marquees as Grant closes Part 1. Figure 2.67, which is a published guessing contest for the 1st Visayan Film Festival, is also a pleasure to see and deserves a whole page. But from a technical standpoint, these primary resources could best be presented with full citations and extensive captions. It is the least one could do to show respect to archival materials and the people who created and took care of them.

Grant and Anissimov are able to construct a viable narrative on Cebuano cinema, and the underlying mournful tone of the narrative is difficult to cast aside--and it should not be. Historiographic problems arise when historical engagements are riddled with romanticism, that is, when things become "fanciful," as Grant puts it. As some form of elegy for Cebuano cinema, Lilas, expectedly, praises that which it loves. It easily opens readers to this, though readers should also remain critical of it.

To this end, Lilas is an essential addition to the dearth of literature on Philippine film history and historiography that also theoretically questions and reimagines concepts of national and regional cinemas. It goes beyond historical inquiries limited to regurgitating names and dates or deciphering styles, practices, and themes. For this, Lilas becomes more than merely a lovely epitaph for a long-forgotten cinema.

Interpretation of a cinema's narratives and identities is only possible with exhaustive research that aims not for the absolute "truth" but, as Eric Smoodin (2007) articulates, seeks to:

[E]xpand the number of interpretable texts and begin to chart the relationships between, and make meaning 
from, various discursive practices. Pedagogically, this means...getting (people) into libraries and other archives; intellectually, it means getting...them to treat movies as aspects of a complex system of cultural production. (p. 18)

If stakeholders and scholars familiar with Cebuano cinema critically engage the facts and conjectures Grant and Anissimov make, then Lilas becomes successful in making people talk about rather than just mourn a cinema that, through such engagements, would hopefully be found again. 


\section{References}

Grant, P.\& Anissimov, M. (2016). Lilas: an illustrated history of the golden ages of Cebuano cinema. Cebu City, Philippines: University of San Carlos Press.

Smoodin, E. (2007). The history of film history. In J. Lewis \& E. Smoodin (Eds.), Looking past the screen. Durham and London: Duke University Press.

BENEDICT SALAZAR OLGADO is an assistant professor at the University of the Philippines School of Library and Information Studies (UPSLIS) teaching archival theory, memory studies, and audiovisual preservation. Prior to joining academia, he served as the inaugural Director of the National Film Archives of the Philippines after receiving his MA in Moving Image Archiving and Preservation from New York University. (corresponding author:b.olgado@slis.upd.edu.ph) 
